\title{
A comunidade do não-lugar: William Morris e utopias passadas e futuras
}

\section{The Non-Place Community: William Morris and Past and Future Utopias}

\section{Rafael Silva Fouto ${ }^{1}$}

\author{
DOI: 10.19177/memorare.v8e12021178-191
}

\begin{abstract}
Resumo: Este artigo analisa a relação de duas obras de baixa ficção científica de William Morris (1834-1896), A Dream of John Ball (1888) e News from Nowhere (1890), comparando-as com os conceitos de comunidade, imunidade, arte e revolta conforme explorados por filósofos como Jean-Luc Nancy, Roberto Esposito, Jacques Rancière e Furio Jesi. William Morris foi um socialista, designer têxtil e escritor inglês durante o período vitoriano, fundador da Socialist League na Inglaterra; os romances aqui explorados trabalham com visões oníricas de potenciais comunidades socialistas ou proto-socialistas, tanto no futuro quanto no passado, e como tais comunidades seriam aos olhos de um viajante temporal inglês do período de Morris. Com base na comparação com diversos filósofos contemporâneos, percebe-se a afinidade do autor com a perspectiva de uma comunidade que rompe com pressupostos e limites bem definidos, sendo por necessidade utópica e inspiradora.
\end{abstract}

Palavras-chave: William Morris. Comunidade. Utopia.

\begin{abstract}
This article analyzes the relation between two works of low science fiction by William Morris (1834-1896), A Dream of John Ball (1888) and News from Nowhere (1890), comparing them with the concepts of community, immunity, art and revolt as explored by philosophers such as Jean-Luc Nancy, Roberto Esposito, Jacques Rancière and Furio Jesi. William Morris was an English socialist, textile designer and writer during the Victorian period, founder of the Socialist League in England; the novels explored here work with dream visions of potential socialist or proto-socialist communities, both in the future and in the past, as well as how such communities would be to the eyes of an English time traveler from Morris' period. Based on the comparison with several contemporary philosophers, the author's affinity with a community that breaks with assumptions and well-defined limits can be perceived, a community that is by necessity utopic and inspiring.

Keywords: William Morris. Community. Utopia.
\end{abstract}

\footnotetext{
1 Doutorando no Programa de Pós-Graduação em Literatura da Universidade Federal de Santa Catarina - UFSC. E-mail: rafaelfouto@gmail.com
} 


\section{Introdução}

A obra talvez mais famosa de William Morris (1834-1896), poeta, designer têxtil, romancista, ativista social e tradutor inglês, é um livro chamado News from Nowhere ("Notícias de Lugar Nenhum"), de 1890, obra de ficção científica fantástica na qual se imagina um futuro utópico em que o comunismo de fato se tornou o lugar comum não apenas na Inglaterra, mas em vários lugares do mundo. 0 título, entretanto, não se limita a isso, recebendo dois subtítulos, sendo um deles A Utopian Romance ("Um Romance Utópico"): Morris sabia o que estava propondo, naquele momento e período. Outra obra do autor, predecessora complementar a News from Nowhere, mas talvez não do mesmo nível de fama, é $A$ Dream of John Ball (sem tradução em português, até a presente data), de 1888, em que está presente o movimento contrário: um trabalho de ficção científica que imagina uma comunidade utópica - mas de outro tipo - no passado medieval da Inglaterra.

O lugar nenhum, ou o não-lugar - "utopia", termo cunhado por Sir Thomas More em 1516, com base no grego ov́ (ou, "não, nenhum") +

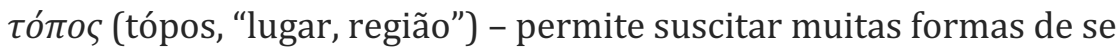
pensar a comunidade como região de potencialidades: o que a comunidade poderia ter sido, continua a poder ser ou poderá ser. Como campo de imaginação, toca a fantasia, palavra também de origem grega,

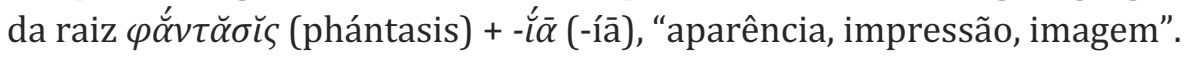
Como Giorgio Agambem disse, "eu não sou jamais isto ou aquilo, mas sempre tal, assim. Eccum sic. Absolutamente. Não possessão, mas limite; não pressuposto, mas exposição" (2013, p. 78). Da mesma forma, podese compreender a comunidade como elemento fugidio à positivação, onde não há pressuposição de um "é" nem de um "este lugar"; pela exposição da fantasia, isto é, da imagem ou percepção de uma potencialidade, um tal-qual, torna-se possível encontrar um ter-lugar dessa comunidade de lugar nenhum. É por meio desse jogo de palavras e ideias que o narrador de News from Nowhere, William Guest - outro jogo, onde o próprio Morris se torna um "Hóspede" (guest) dessa narrativa - homem do século XIX que se mostra constantemente num entre-lugar desse não-lugar utópico, Inglaterra tão familiar como estranha, onde comunidades agrárias podem ser incrivelmente avantgarde, e o futuro maravilhosamente similar ao passado. Em A Dream of John Ball, esse jogo de palavras assume outra potencialidade dentro do fantástico, havendo um narrador sem nome do século XIX, proveniente de Essex (tal como o próprio Morris), assumindo a função de um acadêmico durante a Revolta dos Camponeses de 1381. Porém, este narrador anônimo possui conhecimentos tanto da língua quanto dos eventos que estão acontecendo ao seu redor, ainda que se encontre também em um não-lugar familiar onde, contrariamente, o passado pode ser maravilhosamente similar aos anseios do presente.

Assim sendo, este artigo objetiva analisar uma comunidade que pode vir a ser, dentro da perspectiva das obras supracitadas de William Morris, seguindo por linha de raciocínio e alimento para análise o diálogo com os pensamentos sobre a comunidade, estética e revolta tal como abordados (novamente a talidade presente), principalmente, por Jacques Rancière, Roberto Esposito, Jean-Luc Nancy e Furio Jesi. Nessa 
troca proporcionada pela literatura e seu campo de atuação - isto é, das potencialidades da linguagem - utopia, ficção científica, fantasia e comunidade entrelaçam-se de tal forma a serem complementares uma a outra.

\section{As comunidades de William Morris, entre a revolta e a estética}

0 primeiro aspecto que chama a atenção de William Guest quando acorda numa nova Inglaterra em News from Nowhere é não apenas o dia quente de verão quando deveria ser inverno, mas a ausência da "feia ponte rio abaixo" do Tâmisa. Quando decide nadar na agora límpida água do mesmo rio, Guest explica: "é claro que, ao erguer a cabeça acima da água e olhar na direção da corrente, meus olhos naturalmente procuraram a ponte, e fiquei tão absolutamente assustado com o que vi que me esqueci de nadar e tornei a afundar [...]" (MORRIS, 2019, p. 30). A ponte procurada era a chamada "New" London Bridge, construída em granito e ferro e marca da nova arquitetura do período industrial vitoriano. Entretanto, a ponte que Guest vê é notoriamente diferente:

Talvez eu já houvesse sonhado com esta ponte, mas nunca havia visto uma fora de um manuscrito com iluminuras, pois nem a Ponte Vecchio de Florença lhe chegava aos pés. Era construída de arcos de pedra, esplendidamente maciços, tão graciosos quanto fortes; alta o bastante para deixar passar facilmente o tráfego do rio. Havia sobre o parapeito pequenos edifícios que imaginei serem lojas, cobertas de cataventos e torres pintados em dourado. (MORRIS, 2019, p. 32)

Quão curiosa é essa observação ao leitor, o qual pode esperar apontamentos mais fantásticos de um romance a respeito de um futuro utópico. Entretanto, é justamente na arte e arquitetura em particular que se encontra o foco da ideia de comunismo e comunidade de Morris, de maneira próxima à noção de Rancière de que "la revolución social es hija de la revolución estética [...]" (2013, p. 16). Uma vez que a ponte representa uma estética do passado considerada pelo autor como superior à feia ponte do presente (percebe-se a similaridade arquitetônica e estética com a ponte existente sobre o Tâmisa antes da "New" London Bridge). A qualidade das águas do rio também segue tal passado, sendo límpidas como na época antes da poluição causada pela industrialização de Londres. A lembrança do Grande Fedor (Great Stink) de 1858, causada pelo despejo de dejetos humanos e industriais nas águas e margens do Tâmisa, era ainda uma memória e vivência próxima a Morris; todavia, esse olhar para o passado não deve apenas ser entendido como um desejo de retorno, mas sim um suspiro por mudança. Ao longo de News from Nowhere, William Guest muitas vezes ressalta a superioridade das construções nos locais que visita, não apenas de resistência mas, principalmente, de beleza estética, mesmo em relação às melhores e mais ousadas obras de arquitetura do passado. A revolta estética, nesse sentido, não é apenas uma resposta à industrialização e capitalismo, mas também ao mero funcionalismo e reprodutibilidade presente na arquitetura gerada por ambos. Em um sentimento contrário, olhando para o passado, o narrador de $A$ Dream of John Ball também retira prazer ao observar a arquitetura não metálica e industrial do passado onírico: 
Well, I came into the village, where I did not see (nor by this time expected to see) a single modern building, although many of them were nearly new, notably the church, which was large, and quite ravished my heart with its extreme beauty, elegance, and fitness. The chancel of this was so new that the dust of the stone still lay white on the midsummer grass beneath the carvings of the windows. The houses were almost all built of oak frame-work filled with cob or plaster well whitewashed; though some had their lower stories of rubble-stone, with their windows and doors of well-moulded freestone. There was much curious and inventive carving about most of them; and though some were old and much worn, there was the same look of deftness and trimness, and even beauty [...] (MORRIS, 1888, p. 6) ${ }^{2}$

Em ambas as obras, ressalta-se a importância da relação entre a beleza e a simplicidade das construções, a natureza e a comunidade, uma espelhando na outra os valores observados pelos respectivos narradores. Nesse sentido, a arquitetura e estética caminham em conjunto com o aspecto ecológico no futuro utópico de Morris, em que a intervenção humana no natural ocorre de maneira a intensificar a beleza desta última:

Não preciso me estender sobre os arredores maravilhosos do rio. Observei a ausência [...] das villas de mau gosto; vi também com prazer que as minhas velhas inimigas, as pontes "góticas" de ferro, haviam sido substituídas por belas pontes de madeira ou de pedra. As florestas que cobriam as margens também tinham perdido o ar de capricho característico das reservas de caça e eram agora selvagens e belas, embora as árvores fossem evidentemente bem cuidadas. (MORRIS, 2019, p. 230)

Se é possível considerar a comunidade como elemento constantemente por vir como Agamben (2013) o faz, isto é, uma comunidade que não se concretiza ou se materializa efetivamente no sentido que, uma vez que faça isso, irá normatizar-se e se tornará sociedade, o mesmo pode ser dito da noção de natureza expressa em News from Nowhere: ela pode ser cuidada, mas não regrada e organizada, pois assim perde seu caráter espontâneo e se coisifica; torna-se não natural. Nesse sentido, há quase um elemento artístico presente na ecologia do novo mundo em que William Guest se vê, fruto também da revolta que destruiu o sistema anterior de exploração e mecanização do natural. Complementar, nessa ideia, é também a reação do narrador em A Dream of John Ball, quando primeiro observa a paisagem da Inglaterra medieval que vê em seu sonho, "so that the garden-like neatness and trimness of everything surprised me" (MORRIS, 1888 , p. 5) ${ }^{3}$ : não uma natureza selvagem, mas uma paisagem esteticamente agradável, com o cuidado (e não controle) de mãos humanas. Aqui pode-se considerar a visão de Rancière (2013) sobre o papel da estética nesse novo regime de vida, especialmente no sentido

\footnotetext{
2 "Bom, eu vim para a vila, onde não vi (nem nesse momento esperava ver) uma única construção moderna, apesar que muitas delas eram quase novas, notavelmente a igreja, a qual era grande, e arrebatou consideravelmente o meu coração com sua extrema beleza, elegância e boa condição. A capela desta era tão nova que a poeira da pedra ainda jazia branca na grama do solstício de verão debaixo das entalhaduras das janelas. As casas eram quase todas construídas de estruturas de carvalho preenchidas com argamassa ou reboco bem caiados; ainda que algumas tivessem seus andares inferiores de pedra, com suas janelas e portas de pedra de cantaria bem moldada. Havia muitas entalhaduras curiosas e inventivas sobre a maior parte delas; e ainda que algumas fossem antigas e muito gastas, havia a mesma aparência de destreza e elegância, e até mesmo beleza [...]". Tradução livre minha; doravante, todas as traduções desta obra serão minhas.

3 "de modo que o asseio e a elegância de tudo, à semelhança de um jardim, surpreenderam-me".
} 
da arte que opera sem razão de ser, como um acontecimento, e que pode ser entendida juntamente com a política:

Você não deve acreditar que a nova forma de arte se baseou na memória da arte do passado, embora a guerra civil tenha destruído menos a arte do que outras coisas e apesar de a arte que existira sob as velhas formas ter revivido de forma maravilhosa na parte final da refrega, especialmente a música e a poesia. A arte do prazer no trabalho, como deveria ser chamada, e de que estou lhe falando agora, surgiu de forma quase espontânea de uma espécie de instinto das pessoas que, livres da obrigação desesperada do trabalho excessivo doloroso e terrível, faziam agora da melhor forma possível o trabalho a ser feito; faziam-no com a excelência do melhor de sua espécie. E, depois de algum tempo, surgiu nos homens uma ânsia pela beleza, e eles começaram a ornamentar rude e grosseiramente os artigos que faziam e, uma vez que começaram a trabalhar assim, mais eles insistiram na beleza. (MORRIS, 2019, p. 195)

Assim conta o Velho Hammond a William Guest, quando questionado a respeito da revolta que catapultou o novo mundo comunista experienciado pelo narrador. Aqui encontra-se também uma resposta de Morris a críticas quanto ao abandono do trabalho em um potencial mundo onde o comunismo se deu: o trabalho não seria totalmente deixado a cargo de máquinas porque poderia caminhar juntamente com a arte, na forma do trabalho feito por prazer, tornandose ambos vivos e infindáveis. Essa perspectiva abre outra possibilidade de análise também à noção da obra viva não representável de Rancière, trazida em seu Aisthesis (2013), originalmente mencionada pelo filósofo em relação à obra de arte dramática, mas que também pode ser executada e compartilhada por meio de criações de objetos físicos comuns que não são feitos para exposição, mas para o uso e ressignificação diários. Conforme Rancière compreende,

Los artistas revolucionarios no hacen arte revolucionario. No hacen arte en absoluto. Esto no significa que no haya arte en lo que hacen. Emplean su arte, esto es, su conciencia de las nuevas metas de la vida y su capacidad práctica de hacer, en el trabajo de la materia para transformarla en cosas, elementos materiales de la vida nueva. (RANCIÈRE, 2013, p. 264)

As pessoas na comunidade utópica de Morris, portanto, são revolucionárias pois fazem arte puramente ao fazer qualquer coisa que desejam na vida cotidiana. Da mesma forma, em A Dream of John Ball está presente a consciência da arte no ato de revolta: "'brother,' said John Ball, 'how deemest thou of our adventure? I do not ask thee if thou thinkest we are right to play the play like men, but whether playing like men we shall fail like men"' (MORRIS, 1888, p. 94)4. Aqui a palavra play trabalha em dois sentidos, revolta como verbo, um jogar político, e como substantivo, uma brincadeira ou peça de teatro, onde há o risco de falhar como o homem falha, isto é, ao cair no esquecimento de uma peça mal atuada e, assim, na repetição histórica constante. Morris brinca, dessa forma, com a própria ideia da política como um jogo, perceptível também em News from Nowhere, quando o narrador fica surpreso ao descobrir que as Casas do Parlamento em Londres ainda estão de pé no futuro, e questiona seu recém conhecido amigo, Dick, se elas ainda

\footnotetext{
4 “'irmão', disse John Ball, 'de que modo julgas nossa aventura? Eu não pergunto-te se pensas estarmos corretos em atuar a peça como homens, mas se atuando como homens falharemos como homens".
} 
estavam em uso, recebendo primeiramente uma estrondosa risada como resposta:

Bem que eu o entendo, meu amigo; é inexplicável tê-las deixado de pé, eu sei alguma coisa sobre elas, meu velho parente me deu livros sobre o estranho jogo que ali se praticava. Em uso! Bem, são usadas como uma espécie de mercado secundário e como depósito de esterco, e para isso elas são muito práticas, pois estão exatamente à beira d'água. (MORRIS, 2019, p. 62)

Um estranho jogo que perde sua função dentro da comunidade utópica, uma vez que Morris brinca com a noção de uma política tão suja quando desconectada da arte e do povo, que serviu no máximo como esterco para o adubo da revolta que veio a ocorrer em um futuro em que o comunismo e a comunidade se deram.

Partindo desse pressuposto, cabe ressaltar aqui o entendimento do uso da palavra "revolta" nesse contexto, em contraposição à "revolução", uso abordado particularmente no pensamento de Furio Jesi em Spartakus: enquanto a revolução designa o conjunto de ações que visam a mudança política, econômica e social dentro do tempo histórico, com um projeto de longo prazo, Jesi entende a revolta "[...] como uma suspensão do tempo histórico. A maior parte daqueles que participam de uma revolta escolhem comprometer sua própria individualidade em uma ação cujas consequências não sabem e nem podem prever" (2018, p. 70). Em News from Nowhere, quando Guest questiona o Velho Hammond, historiador que mora no British Museum, a respeito dos eventos que levaram às mudanças sociais como ele observava, recebe primeiramente o exemplo dos resultados iniciais de uma revolução:

Pôs-se em movimento parcial, de forma muito lenta, o maquinário da vida para uso de pessoas que não tinham ideia de sua utilidade, e que na época era conhecido como socialismo de Estado. Mas ele não funcionou bem; os capitalistas sempre resistiram a ele, o que era de se esperar, pois esse sistema tendia cada vez mais a alterar o sistema comercial sem oferecer nada eficaz para substituí-lo. 0 resultado foi confusão crescente, grande sofrimento entre as classes trabalhadoras e, em consequência, grande insatisfação. Durante muito tempo as coisas ficaram nesse pé. (MORRIS, 2019. p. 163)

A tentativa de construir uma mudança política progressiva em direção a um socialismo de Estado na narrativa, desse modo, gerou apenas uma contra-resistência por parte dos conservadores do capital e da sociedade estratificada, bem como um afogamento do proletariado em um mero processo de substituição de um sistema de governo por outro com mecanismos similares. De maneira complementar, o narrador em A Dream of John Ball suscita, também, um dos principais questionamentos de Jesi quanto ao eterno retorno ao mesmo:

But while I pondered all these things, and how men fight and lose the battle, and the thing that they fought for comes about in spite of their defeat, and when it comes turns out not to be what they meant, and other men have to fight for what they meant under another name [...]. (MORRIS, 1888, p. 31) ${ }^{5}$

5 "Mas enquanto eu ponderava todas essas coisas, e como os homens lutam e perdem a batalha, e a coisa pela qual eles lutaram chega apesar de sua derrota, e quando chega acaba por não ser o que eles tinham em mente, e outros homens têm de lutar por aquilo que eles quiseram sob outro nome [...]". 
Todavia, ao contrário do inevitável retorno contido na narrativa histórico-fantástica de John Ball, se tem presente na explicação oferecida a William Guest em News from Nowhere o desejo pela revolta por trás dos esforços revolucionários sistemáticos, conforme essa revolta é entendida por Jesi, em que "[...] a grande força motriz da mudança foi o desejo de liberdade e de igualdade, semelhante talvez à paixão irracional do amante, um mal do coração que rejeitava com ódio a vida solitária e sem sentido dos homens educados e ricos daquele tempo [...]" (MORRIS, 2019, p. 161). Assim sendo, ocorre uma irrupção indisciplinada e um rompimento com o acúmulo estrutural histórico, em forma de uma série de ataques e massacres populares que minaram e finalmente destruíram o sistema vigente. A revolta busca, primariamente, destruição: “Quanto aos 'rebeldes', já lhe disse que a deflagração da guerra fez com que se desinteressassem de salvar as migalhas de riqueza que então tinham. Era comum ouvir deles: a cair novamente na escravidão é preferível destruir todo o país, com exceção dos homens valentes que sobreviverem" (MORRIS, 2019, p. 192).

Desse modo, tal como na revolta de Jesi ocorre uma suspensão do tempo histórico, o capítulo da obra de Morris dedicado à revolta que engatilhou a mudança nessa Inglaterra utópica é também uma suspensão da narrativa, diferindo em narrador (o qual passa a ser o Velho Hammond), e em tamanho em relação aos outros capítulos, um estado de vigília e seriedade que diverge do restante da narrativa, que tende ao aspecto onírico. Essa interrupção pode ser entendida também dentro da visão de Jesi sobre o mito, na qual este suspende o tempo, tal como a revolta contada em News from Nowhere. Esta parece durar de modo não calculável temporalmente, sendo uma pré-narrativa na perspectiva de Guest, o tempo dos deuses do proletário, fora do acesso tanto do narrador quanto do leitor. Nesse sentido, é justamente o elemento de ficção científica (ainda que baixa) da obra que oferece um vislumbre do que esse mito pode ter sido, mesmo que a narrativa, justamente por ser contada a Guest e não experienciada por ele, traga apenas a mitologia descendente desse mito.

Talvez a ideia mais verdadeiramente utópica das obras de Morris, particularmente News from Nowhere, seja o seu próprio conceito de comunidade, o qual atravessa a ideia de communitas de Esposito em seu questionamento base, isto é, do sacrifício existente no dar e doar-se, compartilhamento do munus, da obrigação contraída em relação ao outro. Quando Guest oferece ao barqueiro Dick pagamento pelo passeio proporcionado ao longo do rio, recebe uma resposta inusitada:

Acho que entendo o que você quer dizer. Você acha que eu lhe prestei um serviço; e sente-se obrigado a me dar algo que não devo dar ao meu vizinho, a menos que ele tenha feito alguma coisa especial por mim. Já ouvi falar dessas coisas; mas perdoe-me se lhe digo que acho um costume tortuoso e complicado e não sabemos como fazê-lo. E, veja bem, todo esse trabalho de cruzar o rio, de oferecer às pessoas passeios pela água é o meu negócio, que eu faço para qualquer um; assim, receber presentes por esse negócio me parece muito esquisito. Além disso tudo, se alguém me dá alguma coisa, outra pessoa também poderia dar, e mais outra, e assim por diante; e espero que você não me considere rude quando digo que não saberia onde guardar todos esses presentes de amizade. (MORRIS, 2019, p. 35) 
Há um critério de doação do sujeito implícito nessa relação, em que "un 'deber' une a los sujetos de la comunidad - en el sentido de 'te debo algo', pero no 'me debes algo' -, que hace que no sean enteramente dueños de sí mismos" (ESPOSITO, 2003, p. 30). A reação das pessoas que Guest encontra ao longo da narrativa sempre termina por espelhar a reação do barqueiro, sendo o individualismo do narrador ou, mais especificamente, o seu não doar-se, que se torna fantástico na mente daqueles a quem Guest encontra em sua jornada onírica. A mesma mensagem é apresentada por John Ball no passado, desta vez dentro de um contexto religioso:

Forsooth, brethren, will ye murder the Church any one of you, and go forth a wandering man and lonely, even as Cain did who slew his brother? Ah, my brothers, what an evil doom is this, to be an outcast from the Church, to have none to love you and to speak with you, to be without fellowship! Forsooth, brothers, fellowship is heaven, and lack of fellowship is hell: fellowship is life, and lack of fellowship is death: and the deeds that ye do upon the earth, it is for fellowship's sake that ye do them, and the life that is in it, that shall live on and on for ever, and each one of you part of it, while many a man's life upon the earth from the earth shall wane. (MORRIS, 1888, p. 29) ${ }^{6}$

Esse discurso, entretanto, é irônico, uma vez que John Ball foi notório por pregar contra vários dos mandamentos e dogmas da igreja católica; seu propósito não é, dessa forma, falar da igreja como instituição - vetor de imunização religiosa, na perspectiva de Esposito -, mas sim como uma comunidade, de onde vem seu emprego constante de igreja juntamente com a palavra fellowship, no sentido de "companhia de pessoas que compartilham do mesmo interesse". Viver fora de uma comunidade de companheiros seria assim, viver sem a possibilidade de compartilhamento de experiências, sem lugar de troca e, portanto, em um inferno. Deus, compreende Agamben, “[...] ou o bem, ou o lugar, não têm lugar, mas são o ter-lugar do entes, a sua íntima exterioridade. Divino é o ser-verme do verme, o ser-pedra da pedra" (2013, p. 20). Paraíso seria a tentativa de poder criar essa comunidade do ter-lugar dos entes de maneira duradoura, um esforço em vão na perspectiva de Nancy (2016), uma vez que a comunidade nunca se dá realmente, não possui chegada, e por isso a solução de Ball deve ser tentada e continuada na terra, não no céu. 0 céu torna-se uma mentira de controle das individualidades e experiências, e as instituições que se utilizam disso, o reino e a igreja, são o mal a ser combatido, pois representam uma "[...] redução do ter-lugar das coisas a um facto igual aos outros, o esquecimento da transcendência inerente ao próprio ter-lugar das coisas" (AGAMBEN, 2013, p. 20).

Dessa maneira, John Ball pode ser apresentado na narrativa e na história como revolucionário, tanto dentro quanto fora da igreja. Colocar-se contra as ações do rei Richard III seria colocar-se também contra a instituição da igreja, o que, partindo do pensamento biopolítico

\footnotetext{
6 "Em verdade, irmãos, matareis a Igreja qualquer um de vós, e seguireis em frente um homem errante e solitário, tal como Cain fez que assassinou seu irmão? Ah, meus irmãos, que ruína maligna é essa, ser um exilado da Igreja, não ter ninguém para amar-vos e vos falar, estar sem companhia! Em verdade, irmãos, companhia é o céu, e ausência de companhia é o inferno: companhia é a vida, e ausência de companhia a morte: e os atos que fazeis sobre a terra, é para o bem da companhia que vós os fazeis, e que a vida que está nela, que continuará vivendo e vivendo para sempre, e cada um de vós parte dela, enquanto muitas vidas dos homens sobre a terra da terra minguarão."
} 
de Esposito, vai contra todo o sistema imunitário estabelecido pela união do rei e do divino no corpo de formação do Estado. A fellowship de John Ball e de todos os revoltosos pode ser entendida, dentro da narrativa, como organismos invasores implicados dentro do corpo social inglês, em um momento em que tal corpo já se mostrava enfraquecido pelas guerras na França. De fato, John Ball considera a posição dos revoltosos como tal:

Therefore there is nought that can undo us except our own selves and our hearkening to soft words from those who would slay us. They shall bid us go home and abide peacefully with our wives and children while they, the lords and councillors and lawyers, imagine counsel and remedy for us; and even so shall our own folly bid us; and if we hearken thereto we are undone indeed; for they shall fall upon our peace with war [...] (MORRIS, 1888, p. $71)^{7}$

Os senhores feudais, conselheiros e juristas buscam remedy contra a revolta: aqui a palavra pode ser compreendida em seu duplo sentido, o recurso legal, ou, literalmente, o remédio para desfazer (undone) os corpos revoltosos. Encontra-se, então, a necessidade do discurso de Ball, pois essa incitação à exposição dos corpos ditos invasores em um ataque seria a única maneira de se criar o comum, a fellowship a qual ele menciona, ainda que o risco de uma resposta imunológica desse corpo político atacado possa representar o fim.

Assim sendo, um elemento que as duas obras de Morris lidam fortemente é com a noção de sacrifício, a doação máxima sem a espera de um retorno, tanto no caso da luta do proletário do passado-futuro onírico da comunidade de News from Nowhere, quanto na luta de John Ball e aliados contra as condições de miséria impostas pelo reino no passado onírico de A Dream of John Ball. Neste último, após conversar com o narrador sobre o futuro ainda desigual e desesperador do século XIX, Ball simplesmente diz:

Now, brother, I say farewell; for now verily hath the Day of the Earth come, and thou and I are lonely of each other again; thou hast been a dream to me as I to thee, and sorry and glad have we made each other, as tales of old time and the longing of times to come shall ever make men to be. I go to life and to death, and leave thee; and scarce do I know whether to wish thee some dream of the days beyond thine to tell what shall be, as thou hast told me, for I know not if that shall help or hinder thee; but since we have been kind and very friends, I will not leave thee without a wish of good-will, so at least I wish thee what thou thyself wishest for thyself, and that is hopeful strife and blameless peace, which is to say in one word, life. Farewell, friend. (MORRIS, 1888, p. 126) ${ }^{8}$

Sabendo já que sua morte não ocasionará em mudanças no sistema contra o qual ele luta, ele escolhe o sacrifício mesmo assim, em um ato à

\footnotetext{
7 “Portanto não há nada que possa nos desfazer exceto nós mesmos e nosso prestar atenção a palavras suaves daqueles que nos destruiriam. Eles nos comandarão a ir para casa e residir pacificamente com nossas esposas e filhos enquanto eles, os senhores e conselheiros e juristas, imaginam aconselhamento e remédio para nós; e mesmo assim nossa própria tolice nos comandará; e se prestarmos atenção a isso seremos desfeitos de fato; pois eles cairão sobre nossa paz com guerra [...]". 8 "Agora, irmão, eu digo adeus; pois agora verdadeiramente o Dia da Terra chegou, e tu e eu estaremos solitários um do outro de novo; tu foste um sonho para mim como eu para ti, e pesaroso e feliz nós nos fizemos um ao outro, tal como os contos de tempos passados e o anseio por tempos vindouros sempre farão os homens serem. Eu vou para vida e para morte, e te deixarei; e pouco sei se devo te desejar algum sonho dos dias além dos teus para contar como serão, como tu hás me contado, pois não sei se isso te ajudará ou te entravará; mas já que temos sido gentis e muito amigos, não te deixarei sem um desejo de boa vontade, então pelo menos te desejo o que tu mesmo desejas para ti, e isso é contenda esperançosa e paz sem culpa, que é, para se dizer em uma palavra, vida. Adeus, amigo."
} 
toa, onde ele será destruído junto com todos de seu lado e do lado adversário. Como Georges Bataille aponta, “[...] o ateu está satisfeito com um mundo completo sem Deus; esse sacrificador está, pelo contrário, na angústia diante de um mundo inacabado, inacabável, para sempre ininteligível, que o destrói, o dilacera (e esse mundo se destrói, dilacera a si mesmo)" (2016, p. 174). Espera-se uma compensação divina pela avareza e repetição do ciclo humano, em que John Ball e a fellowship criada por ele se cedem em busca de pequenas mudanças e novas fellowships, já que as grandes mudanças não irão ocorrer; assim, se tem o desejo por "contendas esperançosas" e "paz sem culpa", a vida, como ele resume, algo que o próprio Ball não pode possuir em nenhuma instância, olhando então para o sacrifício e para a morte.

Em News from Nowhere, no distante século 22, este desejo de Ball no então passado medieval de $A$ Dream of John Ball é alcançado finalmente, mas ao mesmo tempo o próprio entendimento do significado do sacrifício não é mais observado por aqueles que vivem a mudança de fato. Essa situação chega a tal nível que o Velho Hammond durante a explicação da revolta preocupa-se de estar “[...] usando palavras e frases que poucos dentre nós compreenderiam sem uma longa e laboriosa explicação, talvez nem mesmo com ela" (MORRIS, 2019, p. 168); o próprio sacrifício é sacrificado para se chegar ao ponto da mudança visualizada por Morris. De fato, o estudo da história como um todo é deixado de lado dentro do mundo futurístico de News from Nowhere, chocando o narrador quando este questiona se as crianças aprendem algo do conhecimento histórico: “[...] 'de fato, acho que a maioria não aprende. Ouvi meu bisavô dizer que é principalmente nos períodos de agitação, de guerra e confusão que as pessoas se interessam pela história, e você sabe', disse meu amigo com um sorriso amável, 'hoje não somos mais assim'” (MORRIS, 2019, p. 60)

Outro ponto fraco dessa communitas utópica localiza-se justamente no risco da perda do individual no comunitário, conforme apontado por Esposito. Isto não é ignorado totalmente nas obras de Morris, visto que uma voz dissidente da sociedade comunista do futuro aparece em News from Nowhere:

"Bem, senhor, fico feliz em ver um homem de além-mar, mas diga por favor se vocês não vivem melhor no seu país, onde, suponho, todos são mais vivos e animados por não terem abandonado totalmente a concorrência. Li muitos livros de dias passados e, com certeza, eles são mais vivos do que os que se escrevem hoje; todos foram escritos sob as condições da boa concorrência. Se o registro da história não o informasse, aí estão os próprios livros a demonstrá-lo. Há neles um espírito de aventura e sinais da capacidade de extrair o bom do mau que não existe na nossa literatura; acredito que nossos moralistas e historiadores exageram muito a infelicidade do passado, quando se produziram tão esplêndidas obras de imaginação." (MORRIS, 2019, p. 215)

Essa fala pertence a um velho considerado resmungão pelos outros habitantes e mesmo por sua neta Ellen, um personagem que não é nomeado em nenhum momento, sendo referido apenas como "velho" ou "avô de Ellen", uma das personagens introduzidas mais ao final da visita de Guest. A inversão de posicionamentos na comunidade reforça o caráter fantasioso e onírico desse mundo onde a comunidade pôde de fato se dar, em que todos os que têm perspectivas similares voltadas ao 
doar-se possuem um nome, e aquele que tem uma voz dissonante e individualista dentro dessa comunidade permanece sem nome e malvisto. Subentende-se, é claro, que a visão desse velho representa um olhar de retorno ao passado capitalista, particularmente à concorrência do mercado. Ainda assim, seu enfoque na vividez da imaginação individual, proporcionada pela desigualdade de classes, traz à tona uma das problemáticas e dos perigos dessa comunidade, no sentido de esta ter o potencial, em seu sacrifício e obrigação contraída de dever ao outro que se expande a todos os membros, de anular o pensamento que lhes é diferente. Desse modo, o velho suscita dentro da narrativa a ideia de immunitas de Esposito, no sentido do benefício de dispensa da dívida estabelecida pela communitas, isto é, de uma reação a uma tentativa de ordenação que, ainda que não legalmente regrada e estabelecida (pois não há um real senso de sociedade no mundo que Guest observa), ronda as comunidades no risco da normalização do pensamento. Ao mesmo tempo, o fato do velho ser visto apenas como um resmungão - um ingrato imunizado - e ter liberdade para dizer o que quiser sem em nenhum momento ser calado demonstra aceitação de sua voz dentro da comunidade, lembrando o pensamento de Nancy (2016) no entendimento da comunidade como um consenso de dissensos, da partilha e difusão de identidades dentro de uma pluralidade.

Ainda assim, a immunitas como resposta ao exterior dentro dessa comunidade também está presente na própria figura de William Guest, alienígena em todos os sentidos salvo o de ser "nativo" a terra (e apenas à terra) onde se encontra, e onde conversar sobre o mundo velho lhe serve "[...] como um cobertor a me proteger do frio desse mundo novo, onde eu estava sendo, de certa forma, desnudado de todos os pensamentos e formas de agir habituais" (MORRIS, 2019, p. 159). Temse por parte das pessoas que Guest entra em contato uma resposta quase biológica - ou, nesse sentido, biopolítica - a uma presença desconhecida dentro da comunidade. De uma perspectiva de imunização dentro do sistema social, conforme explica Esposito, “[...] uno está incluido por exclusión y excluido por inclusión. Em términos sistémicos se incluye excluyendo, se une separando, se vincula diferenciando" (2002, p. 71). É sendo desnudado e desconstruído que William Guest se inclui dentro do sistema novo em que se encontra, sua diferença e exclusão sendo os pontos que o conectam ao novo sistema social, o qual o recebe por meio dos indivíduos que o constitui, mas o ajusta e domestica por meio de sua visão de mundo sistêmica. Aí se encontra o perigo da ordenação e unissonização de vozes, que culmina na transformação de comunidades em sociedades.

Um dos resultados do novo modo de vida proporcionado pela revolta na obra adentra um aspecto pelo qual News from Nowhere se expõe a críticas, que é o da pouca importância dada à leitura e livros nas comunidades descritas por Morris, crítica essa inclusa na própria fala do velho resmungão. A fala de Ellen em resposta ao avô contém elementos que merecem também ser considerados em uma perspectiva estética:

Livros, livros! Sempre os livros, vovô! Quando você vai entender que, afinal, é o mundo em que vivemos que deveria nos interessar, o mundo de que fazemos parte e a que nunca vamos amar demais? Veja!" Ela abriu a janela e nos mostrou as luzes brancas que brilhavam entre as sombras do

Memorare, Tubarão, v. 8, n. 1, jan./jun. 2021. ISSN: 2358-0593 
jardim enluarado, por onde corria a brisa noturna do verão. "Veja! São esses os nossos livros hoje! - e esses", ela disse, aproximando-se dos dois amantes e colocando as mãos nos seus ombros, "e o nosso amigo com seu conhecimento e experiência de outras terras - e até você, vovô" (um sorriso se abriu no seu rosto ao dizê-lo), "apesar de toda a rabugice e da saudade dos tempos idos [...]. É isso, esses são nossos livros e, se quisermos mais, não encontramos trabalho nos belos edifícios que erguemos por todo o país (e eu sei que no passado nunca existiu nada igual), nos quais cada homem oferece o que de melhor tem e faz com que suas mãos exprimam sua mente e sua alma? (MORRIS, 2019, p. 216)

Cabe aqui trazer novamente Rancière e seus questionamentos quanto à noção de emancipação, uma vez que o avô de Ellen utiliza-se da arte passada, na forma dos livros, como exemplo de superioridade do passado e, mais especificamente, como figura de autoridade desse passado. Desta forma, ele positiva a arte, enquanto Ellen reforça o caráter da atuação no mundo, livros escritos e lidos constantemente na partilha de experiências e linguagens diferentes. Há, assim, por meio do embaralhamento entre as diversas atividades praticadas pelas pessoas na narrativa e os diversos momentos de passividade e observação, tanto do narrador Guest quanto das personagens que ele encontra, a emancipação dessa comunidade utópica. A crítica dos personagens ao velho rabugento não é, necessariamente, ao valor que ele dá aos livros e ao passado, mas à maneira como ele traz uma leitura de mundo que tenta constantemente direcionar e fechar a conversa, o que o leva a assumir função dupla: de dissenso em relação ao mundo comunista apresentado por Morris, e de consenso em relação ao mundo capitalista do leitor.

Em ambas as narrativas, percebe-se uma grande relevância dada às paixões dos indivíduos dentro do âmbito da partilha com o outro; conforme pensa Nancy a respeito da comunidade inoperada, esta se encontra ao lado do conceito de "sagrado" de Bataille, onde há um desencadeamento de paixões que ocorre na comunicação com o outro e, portanto, não é limitado ou dominado totalmente pelo subjetivo (NANCY, 2016, p. 64). Pode-se compreender, nesse sentido, que a comunidade conforme aparece nas obras de Morris aborda tal ideia de partilha, exemplificada em News from Nowhere pelo Velho Hammond e sua paixão em comunicar seus conhecimentos: "'francamente, caro hóspede, se você espera que eu ponha a língua a trabalhar, saiba que está me prestando um grande favor. 0 amor à conversa mora comigo, ou melhor, cresce comigo [...]" (MORRIS, 2019, p. 93). Do mesmo modo, há longas conversas entre Guest e cada personagem que encontra na narrativa, bem como entre John Ball e o narrador de A Dream of John Ball, constantemente marcadas pela paixão por uma causa, arte ou fazer específico. Pode-se dizer que é apenas nessa comunicação que a singularidade da identidade de ambos os narradores é exposta para o fora deles mesmos, conforme o entende Nancy:

Nós somos semelhantes porque somos, cada um, expostos ao que nós somos para nós mesmos. 0 semelhante não é o parecido. Eu não me encontro, nem me reconheço no outro: eu vivo essa experiência ou experiencio no outro a alteridade e a alteração que "em mim mesmo" coloca para fora de mim a minha singularidade e que a finda infinitamente. (NANCY, 2016, p. 66) 
O semelhante dos narradores é preconizado no deslocamento deles para um outro tempo, passado ou futuro, em relação ao seu tempo de origem, no qual vivem uma vida solitária de não partilha, a qual inevitavelmente devem retornar ao fim de seus respectivos sonhos, como ocorre com o narrador anônimo de A Dream of John Ball: "but as I turned away shivering and downhearted, on a sudden came the frightful noise of the 'hooters,' one after the other, that call the workmen to the factories, this one the after-breakfast one, more by token"9 (MORRIS, 1888, p. 128). Da mesma forma, William Guest reconhece a não pertença ao futuro utópico que visitou, ouvindo a voz de Ellen em sua cabeça ao acordar:

Não adianta, você não pode ser um de nós; você é parte tão integral da infelicidade do passado que talvez nossa felicidade fosse apenas tediosa para você. Volte, agora você já nos viu e seus olhos aprenderam que, apesar de todas as máximas infalíveis de seu tempo, ainda se pode esperar um tempo de paz para o mundo, quando a dominação se tiver transformado em companheirismo - mas não antes. (MORRIS, 2019, p. 295)

Ambos os narradores experienciaram uma alteridade no outro contido em outra temporalidade, que lhes permitiu conjecturar e negociar suas próprias identidades no relacionamento com esses outros, ecoando dessa forma a noção da comunidade enquanto "[...] regime ontológico singular no qual o outro e o mesmo são semelhantes: ou seja, a partilha de identidade" (NANCY, 2016, p. 66).

\section{Considerações finais}

Foi proposta aqui uma discussão a respeito de uma comunidade dentro de potencialidades do ser e do estar nos romances de ficção científica de William Morris, perpassando diversos aspectos da doação e imunização dentro do comunal, a presença da estética no político e na partilha em ambas as obras, bem como a revolta como ponto de grande importância na formação das comunidades utópicas na visão do autor. Foi possível perceber que há um elemento do fantástico nas duas obras analisadas que não se encontra no âmbito de mundos secundários altamente tecnológicos e futuristas inventados pelo autor, ou na presença de criaturas como elfos e dragões em um passado distante; o fantástico localiza-se no pensar fora do pensamento pré-estabelecido, no não-lugar mostrado nas imagens de um passado medieval em que os germes do comunismo já estavam presentes (anacronismo impensável pela perspectiva da História) ou de um mundo futuro low tech e agrário em que todos os pressupostos econômicos, sociais e culturais contemporâneos não existem como compreendidos agora. Tem-se um exercício de pensamento filosófico que é propositadamente avesso a pressupostos, voltado a noções tensionais de comunidade. Uma vez que se pense que no literário não se pode ter sociedade, um fechamento ordenado e regrado em voz uníssona - o que se tem nos dois romances de Morris, e particularmente em News from Nowhere - é vista a comunidade em relação a algo ou alguém: seja o algo a sociedade inglesa

\footnotetext{
9 “mas quando me virei tremendo e desanimado, subitamente veio o temível barulho das 'sirenes', um depois do outro, que chamavam os trabalhadores para as fábricas, esta a sirene pós-café da manhã, como prova adicional.”
} 
vitoriana (ou mesmo a contemporânea globalizada), seja o narrador ou o próprio leitor. Essa comunidade imaginária está, dessa forma, sempre se dando e nunca dada, construindo-se tanto na narrativa quanto no pensamento do leitor, sendo fantástica na maneira também como traz a hesitação entre o real e o ilusório. Tal como o não-lugar do sonho empregado por Morris, a comunidade estética imaginada pelo autor suscita o onírico dentro da realidade, e o questionamento de utopias em momentos de distopias na conjunção histórica e social atual.

\section{Referências}

AGAMBEN, Giorgio. A comunidade que vem. Tradução de Cláudio Oliveira. Bahia: Autêntica, 2013.

BATAILLE, Georges. A experiência interior, seguida de método de meditação. Tradução de Fernando Scheibe. Bahia: Autêntica, 2016.

ESPOSITO, Roberto. Communitas: origen y destino de la comunidad. Tradução de Carlos R. Molinar Marotto. Bs As: Amorrortu, 2003.

Immunitas: protección y negación de la vida. Tradução de Luciano Padilla López. Bs As: Amorrortu, 2005.

JESI, Furio. Spartakus: simbologia da revolta. Tradução de Vinícius Nicastro Honesko. São Paulo: n-1, 2018.

MORRIS, William. A dream of John Ball and a king's lesson. London: Reeves \& Turner, 1888.

. Notícias de lugar nenhum, ou uma época de tranquilidade: um romance utópico. Tradução de Paulo Cezar Castanheira. São Paulo: Expressão Popular, 2019.

NANCY, Jean-Luc. A comunidade inoperada. Tradução de Soraya Guimarães Hoepfner. Rio de Janeiro: 7 Letras, 2016.

RANCIÈRE, Jacques. Aisthesis: escenas del régimen estético del arte. Tradução de Horacio Pons. Bs As: Manantial, 2013.

Artigo enviado em: 20/04/2021. Aprovado em: 24/05/2021. 